\title{
Application of Geostatistical Characteristics of Rock Mass Fracture Systems in 3D Model Generation
}

A. Rafiee*, M. Vinches

Alès School of Mines, France

\begin{abstract}
:
The mechanical behaviour and the state of stability of a jointed rock mass depend on how the fracture systems were propagated in this medium. In fact, obtaining an accurate description of the fracture spatial distribution is one of the main problems to be solved in rock mass stability studies. The purpose of this paper is to apply the geostatistical method to find the spatial correlation between joint systems. Geostatistics enable us to quantify the spatial characteristics of fracture patterns, which can not be derived by ordinary statistical method or structural analysis. The combination of the traditional method used in structural analysis and of the geostatistical method is used in order to get a better insight into the fracture distribution in the rock mass. The results obtained, are then applied to generate 3D numerical jointed rock mass models.
\end{abstract}

\section{Introduction}

The rock mechanics and fluid transport properties of the rock mass depend mainly on the characteristics of the fracture field. Fractures are only accessible at their intersections with outcrops, boreholes or drifts: one of the first steps in fractured rock mass studies is to make assumptions about the fracture geometry, and to simulate the fracture field.

The modelling of a fractured rock mass is complex and depends on multiple parameters. Therefore, because of existing constraints in field surveys and incomplete data, it is necessary to extract as much information as possible from the data which has been collected. This is one of the reasons for the application of sophisticated methods to obtain the fundamental spatial characteristics of fracture systems. 
This type of study can be performed on different scales: on large faults, on fractures and on microjoints. For each category two separate features can be studied:

1- The fracture network: each element is considered as relatively simple (i.e., a planar fracture), and the study is concerned with the imbrications of the various elements.

2- The single fracture: generally an open fracture is not a pair of parallel planes; there are voids and contact areas that depend on stress and have a high influence on the mechanical behaviour of the fracture.

The fractal and geostatistical approaches are used to study the single fracture [1-13]. The scope of this work, the ultimate aim of which is the study of the mechanical behaviour of the fractured rock mass, is focused on the study of the fracture network. In such studies, because we have very limited data in comparison with the size of the model that will be simulated, deterministic modelling is often impossible. In this case, stochastic modelling is needed. Much work has been carried out to characterize a fracture network by the integration of the statistical properties of the fracture system such as distribution of orientation, trace length, spacing and aperture in the models [14-31]. The fractal method has been applied in some cases for studying the fracture network. Geostatistical techniques have also been used to study the regionalized characteristics of the fracture network [32-40]. The high complexity of this network requires the results from all of these methods to produce a realistic model.

The approach proposed here combines the geostatistical method and the usual structural geological analysis. First, the semivariogram analysis is used for all of the data sets, in this case for the fracture density, and afterwards the same method is used for the data grouped by structural analysis. The fracture density, and the fracture orientation characteristics are often the predominant factors in the stability of rock slopes. These two factors contribute to the definition of the vulnerability of the rock mass. The use of this combination of methods will be illustrated within the framework of a real case study. 


\section{Data sets based on fracture orientation}

As previously mentioned, we use the orientation data sets measured within the framework of road widening in the Pyrenees region. This 600 meter long project, on a main road crosses mountainous territory (Fig.1) [41]. The uphill and downhill slope of the present road will have to be cleared of the blocks likely to be destabilized by vibrations.

The road cuts through both migmatites and micaschists. Discontinuity orientation data are obtained by means of compass measurements of discontinuities that intersect with the scanline positioned on the exposed rock faces (Fig.1b). The fracture measurements were carried out on nine scanlines: six in the migmatite and three in the micaschist. In this study, we chose the scanline on which a significant number of fracture measurements was collected for geostatistical analysis. Scanline number 1, in the migmatite with 392 measured fractures, is 90 $\mathrm{m}$ long. The adequate scanline for a geostatistic analysis depends upon several parameters, particularly the fracture density and the scale of the study.

The grouping of discontinuities into principal discontinuity sets for this scanline is performed by the spectral clustering method that is a recent approach proposed by R. JimenezRodriguez and N. Sitar [42]. We developed a code in the R environment on the basis of their algorithm, see details of this algorithm in [42].

In Fig.2, we present the computed partitions of the spectral clustering in the lower hemisphere projection when four principal families are considered for all the data sets. Calculating the direction of the average unit normal vectors for each discontinuity set and partitioning the data in four families was performed on the fractures that are not very distant from the reference point of each family. Consequently here, certain fractures have been assumed not to belong to any of these four families. Fig. 3 shows the results of the spectral clustering for 315 fracture orientations located in the vicinity less than $25^{\circ}$ from the average direction of each family. As a result, the pole points labelled with the $*$ symbols were not taken 
into account for the average point calculations. They represent, in our case, nearly $20 \%$ of the complete data set. The choice of $25^{\circ}$ for the vicinity angle was made by comparing the results obtained for different vicinity angles. In fact, in order to calculate more adequately the representative points for each fracture set, it is necessary to eliminate the points located away from the centre of each set. However, using 25 degrees in this elimination step, a large amount of data is not lost as would have been the case for $5^{\circ}, 10^{\circ}, 15^{\circ}$ and $20^{\circ}$ vicinity angles. The high vicinity angle also leads to having more marginal points in the set, and consequently decreases the pertinence of the representative point. Therefore, in Fig. 3 by choosing the vicinity angle of $25^{\circ}$, we tried to eliminate the marginal points and also to keep a reasonable number of points for the next steps of data processing.

Table 1 shows that the average normal vectors for each discontinuity set and the number of fractures belonging to each family based on the calculation displayed in Fig.3. The average of the normal set spacing in $\mathrm{cm}$ for each fracture set is also presented in Table 1 (the set spacing measured along a line that is perpendicular to the mean orientation of a particular set).

\section{Statistical characteristics of the fracture density}

For each set, the fracture spacing is measured by the real distance separating successive intersections, on the scanline, of fractures belonging to this set. The discontinuity spacing is widely used as a measure of the quality of a rock mass in several engineering classifications. The inverse of the mean spacing is the average density of intersections along the scanline. The frequency histogram for the normal spacing values of four joint sets (Fig. 4) appears to follow the general shape of the exponential distribution. This distribution may be expressed as

$$
f(x)=\lambda e^{-\lambda x}
$$


where $f(x)$ is the frequency of a discontinuity spacing $\mathrm{x}$, and $\lambda$ is the average number of discontinuities per metre. It should be noted that the exponential distribution for discontinuity spacing distribution was recommended by Priest and Hudson [43,44].

Discontinuity frequency (density) is one of the fundamental measures of the degree of fracturing of the rock mass. Frequency can be expressed in terms of the number of discontinuities that are observed or predicted to occur in a unit volume, a unit area or a unit length of a sample from a given rock mass $[43,44]$. In this study, frequency is used as a variable for geostatistical analysis as explained in the next section. A histogram for the discontinuity frequency for all four sets in $2 \mathrm{~m}$ long segments is presented in Fig. 5.

\section{Geostatistical approach}

Geostatistical approaches can be used to investigate the spatial behaviour of a variable. In our case, this variable can be a characteristic of a fractured rock mass such as spacing, fracture length and fracture frequency. This can lead to a better understanding of the spatial distribution and structure of the variable. The semi-variogram $\gamma(\mathrm{h})$ is a function describing the degree of spatial dependence of a spatial random field or stochastic process $\mathrm{Z}(\mathrm{x})$. In this study, the fracture density is considered as the variable $\mathrm{Z}(\mathrm{x})$, and its semi-variogram is calculated by numbering the fractures observed in the defined segments along the scanline. The semi-variogram indicates how different the values become as the distance $h$ between two points increases. In fact, for the fracture density case, the semi-variogram can be defined as a measure of half of the average of the square difference between the number of fractures (in equal segment size) a distance $h$ apart. The semi-variogram of fracture density is defined as:

$$
\gamma(h)=\frac{1}{2 N} \sum_{i=1}^{N}\left(Z\left(x_{i}+h\right)-Z\left(x_{i}\right)\right)^{2}
$$

where $x$ and $x+h$ refer to points in an $n$-dimensional space where $n$ could be 1,2 or 3 . For the fracture density case, using a scanline, $\mathrm{n}$ is considered equal to 1 . The parameter $\mathrm{N}$ represents the number of pairs for the distance $h[45,46]$. 
The semi-variogram summarizes the dissimilarity or represents the statistical mean of the square of the estimation error of $\mathrm{Z}$ (here the fracture density) between two points, a distance $\mathrm{h}$ apart. We subdivide a surveying line into equal segments of length $b$. Then for distances $h=b$, $2 b, 3 b \ldots$, we compute the semi-variogram of the number of intersections per segments.

Fig. 6 illustrates the average experimental semi-variograms for the fracture densities with the segment sizes of $0.5 \mathrm{~m}, 1 \mathrm{~m}, 1.5 \mathrm{~m}$ and $2 \mathrm{~m}$. This figure enables us to compare the characteristics of the semi-variograms calculated for different segment sizes. It can be seen immediately, as expected from the regularisation theory, that the $2 \mathrm{~m}$ semi-variogram has the lowest nugget effect and the lowest sill value. On the other hand, these four semi-variograms represent nearly the same structure. In fact, all of them exhibit periodic behaviour with the same interval of approximately $12 \mathrm{~m}$.

Experimental semi-variograms often increase continuously with distance; however, the semi-variogram is not restricted to such monotonic forms: decreasing segments or cyclical patterns can be observed. Non-monotonic semi-variogram structures are identified as "holeeffect" structures [47]. Hole-effect structures most often indicate a form of periodicity, which is a common and legitimate spatial characteristic in geology. Ignoring these non-monotonic structures may result in unrealistic heterogeneity models that do not reproduce the observed patterns of variability.

In addition, as the segment size increases and progressively reaches values similar to the length of the characteristic periodic interval, the periodic structure becomes less apparent. The segment size of $2 \mathrm{~m}$ was chosen in this study, for the geostatistical analysis, by considering the loss and weakness of the periodic structure for segment sizes higher than $2 \mathrm{~m}$ and the frequency distribution (Fig.5) which is nearly normal for this segment size. It should be noted that the frequency distribution for three other segment sizes were far from the normal distribution. 
Because of the high influence of the variable distribution on the experimental semi-variogram calculation, the data of the $2 \mathrm{~m}$ long segments were preferred $[45,46]$.

In order to better understand the origin of this cyclical pattern, experimental semi-variograms were separately calculated for all four fracture sets. Fig.7 shows the fracture density semivariograms obtained for the four discontinuity sets. As can be observed in these semivariograms, three of them have nearly the same behaviour, but the variogram of the second set (Fig. 7b) presents a form similar to the variogram obtained for all fractures (Fig.6). This remark can explain that this particular behaviour of the fracture density variogram for all the discontinuities, illustrated in Fig. 6, derives only from the fractures belonging to the second set. As with the variogram in Fig. 6, we have the same hole-effect behaviour for the variogram of the fracture density for the second set with the same periodic distance of $12 \mathrm{~m}$.

In addition, in order to demonstrate that this similarity corresponds only to the second set, the semi-variogram of all the discontinuities without those of the second set is computed. Fig. 8 shows the semi-variogram calculated from these data. There is no similarity between this variogram and the variogram illustrated in Fig. 6. As a result, the discontinuities of the second set are the source of the hole-effect behaviour of the semi-variogram in Fig. 6 .

\section{3D model generation}

After the statistical and geostatistical analysis explained in the previous sections, the results obtained are used to generate a 3D fractured rock mass model. This model is simulated by considering three distinct phases: fracture surface generation set by set, intersection of the different sets with a hierarchical order, and finally identification of individual blocks.

\subsection{Fracture surface generation set by set}

Two steps are necessary for this phase. The first step will generate the fracture sets that do not have an obvious spatial structure: the generation of these sets relies only on their statistical 
characteristics. The second step consists in identifying the fracture sets presenting a quasiperiodic structure in their semi-variogram and generating the fracture sets using their revealed geostatistical characteristics.

Concerning the first step, we generate in our example the discontinuities of sets 1, 3 and 4 . It should be mentioned that the hierarchical method is used only during the intersection phase (see below), where the primary geometry is divided into separated blocks by the previously stochastically generated fracture surfaces. Consequently, it is not necessary to apply the hierarchical procedure for this phase of fracture surface generation.

These sets do not show a particular structure in their semi-variograms. As a result, their fracture systems are generated by considering only their statistical characteristics: mean value and standard deviation derived from their spacing distribution. For this purpose, we developed a code written in the Visual Basic language in the AutoCAD® software. The flow chart of the model process is shown in Fig.9a for the model generated by considering the simple statistical characteristics. These three sets are not necessarily generated in the direction of the scanline. However, for the second set this issue was taken into account by considering its observed structure in this direction. The position of first fracture surface in the space for each set is generated using the uniform law. The rest of the fractures are then generated parallel to this surface by taking into account the statistical characteristics of the spacing distribution.

A jointed rock mass is simulated by generating a joint pattern that is statistically based on the joint spacing, the orientation data and the persistence of each fracture set. It should be noted that in this study, fracture is initially considered as an infinite planar surface, taking into account the average orientation parameter (Table 1) and the spacing distribution. However, this infinite planar surface can then be pivoted during the intersection phase by a given tolerance concerning its dip and strike. As a result, each fracture surface can take different orientations inside its tolerance range, whenever it is called by the code in the intersection phase. The joint spacing 
parameter for this study is assigned an exponential distribution by equation (1) and is obtained by a random generator algorithm. Then the rejection method is used to ensure that these randomly generated spacing values fall within the desired distribution [48].

For orientation data, the results shown in Table 1 are used to generate four fracture sets. It should be mentioned that the code user can give the tolerance angle for strike and dip value by taking into account Fig. 3. The orientation data are assumed to follow a normal law and the program takes the mean and standard deviation of the fitted distribution for each fracture set as input parameters.

The second step of the fracture model generation concerns the fracture set whose semivariogram has a special behaviour. For this type of set, the characteristics of the density semivariogram in addition to its statistic features are taken into account in the program. The model is generated by considering the $2 \mathrm{~m}$ long segments and by obtaining similar behaviour in the semi-variogram, for the numerically generated fractures. This step is performed by using a special code developed in the $\mathrm{R}$ environment which uses geostatistical tools. In fact, the characteristics such as segment size, range, maximum and minimum number of fractures per segment and the standard deviation of the density distribution are used to generate the model with the same statistic and geostatistic features. Besides, the user of the code can compare the semi-variogram of the model with the semi-variogram of the raw data, and accept or reject it. In case of rejection, a new simulation is performed until a good enough fitting of the numerical model and the experimental results is obtained. The fracture density semi-variogram obtained in this way for the second set is displayed in Fig. 10. It presents the same periodic forms $12 \mathrm{~m}$ apart and similar other parameters (apparent sill and drift).

The data generated for calculating the model semi-variogram is then employed in the Auto Cad code, as previously explained, to generate a fracture system by considering the number of fractures per segment and the statistical parameters of spacing distribution for this set. 
Therefore, this set is generated segment by segment in order to respect its semi-variogram attributes. It should be noted that because of the limited number of fractures per segment, the statistical parameters used in this step for the second set are obtained from its whole data, but simultaneously the number of fractures per segment corresponds to the number determined by semi-variogram analysis.

\subsection{Intersection of fracture sets with a hierarchical order}

Persistence is a necessary parameter for the generation of the fractured model in the intersection phase. Persistence (joint continuity) is defined as the probability that any joint cuts a block that lies in its path [49-51]. It can be considered as a substitution parameter for joint length. Persistence can have a value of between 0 and 1 . In addition, it is the persistence parameter that determines the state of the fracture termination when intersecting with pregenerated ones. For a persistence value near to 1, there will be more fractures that go through pre-existing fractures. For values near to 0 , the new fractures end when intersecting with preexisting ones. The approximate persistence value for each fracture set can be determined by comparing the fracture length distribution obtained from the field survey with the distribution resulting from the generated test model. It should be noted that this comparison must be carried out on the same scanline direction. This part of the program is a very time-consuming but necessary task, in order to obtain a realistic model.

Once all the fracture sets are generated, on the basis of notes taken during the field measurement, the order of sets is defined [52]. Indeed, there are three possibilities for ordering including hierarchical, random or hybrid methods. In this case, the hierarchical method $\left(1^{\text {st }}, 2^{\text {nd }}\right.$, $3^{\text {rd }}$ and finally $4^{\text {th }}$ set) is used for the model generation. Fig. 11 illustrates the results of a 3D model generation in which four discontinuity sets are incorporated. This figure shows how fracture sets are included in the model in a hierarchical way: first with two sets, then with the inclusion of the two others. The persistence values used in this model are $0.45,0.35,0.3$ and 
0.2 respectively for $1^{\text {st }}, 2^{\text {nd }}, 3^{\text {rd }}$ and $4^{\text {th }}$ fracture sets. It should be remarked that these persistence values have been determined by a trial-and-error approach to obtain fracture trace length distributions in the scanline direction, similar to the in-situ measured distributions.

\subsection{Identification of individual blocks}

Because the aim of this code is to use the generated model for numerical simulation, another possibility is added to the code to avoid having blocks smaller than a determined volume. In other words, the code user can determine the threshold value for the minimum block volume.

By considering the existing abilities in the Auto Cad environment and several auxiliary codes developed in this software, each generated block is considered as a distinct entity. A series of codes are also developed for data acquisition from the generated model. The developed programs enable us to obtain data such as block volume distribution, area and orientation of the block facets and block vertices coordinates. The block volume distributions shown in Fig.11 are examples of their application. In this model the volume threshold value is $0.25 \mathrm{~m}^{3}$ and the final model has 19227 stochastically generated blocks.

\section{Conclusion}

Understanding the discontinuity spatial distribution of a rock mass has important applications in the field of rock engineering. As a result, applying statistical and particularly geostatistical techniques is useful to reveal the spatial characteristics of fracture systems. These characteristics generally vary according to a large number of parameters such as the rock mass type, or the tectonic situation. Therefore, the different combinations of statistical techniques should be used by taking into account the diverse geological and tectonic conditions. In this study, we have illustrated the application of the geostatistical technique combined with the traditional methods to reveal the main characteristics of the fracture spatial distribution. The importance of separating the fractures into distinct sets was demonstrated by illustrating their different spatial behaviour. One of the main goals of this study is to show the usefulness of a 
geostatistical analysis in order to distinguish the spatial characteristics of the discontinuity distributions that are beyond the capabilities of the simple statistical and traditional methods.

The results are used to generate a realistic 3D rock mass model. Such a model can then be used in different applications such as rock mass stability analysis, planning the exploitation system, or size estimation of exploitable rock blocks depending on the project goals.

\section{Acknowledgments:}

The authors wish to thank M. Gasc-Barbier, D. Virely ,J. Guittard and the personnel of the the "Laboratoire Régional des Ponts et Chaussées de Toulouse" who made their measurements data and the technical report of the case used in this paper available.

\section{References :}

[1] Belem T, Homand-Etienne F, Souley M. Fractal analysis of shear joint roughness. Int J Rock Mech Min Sci 1997; 34: Paper No.130.

[2] Ehlen J. Fractal analysis of joint patterns in granite. Int J Rock Mech Min Sci 2000; 37:909922.

[3] Hamdi E., A fractal description of simulated 3D discontinuity networks. Rock Mech Rock Eng, 2003, submitted for publication.

[4] Huang SL, Oelfke SM, Speck RC. Applicability of fractal characterization and modeling to rock joint profiles. Int J Rock Mech Min Sci Geomech Abstr 1992; 29:89-98.

[5] Mandelbrot BB. The Fractal Geometry of Nature. New York: W. H. Freeman and Co., 1982, pp 468.

[6] Mandelbrot BB. Self-affine fractals and fractal dimension, Physica Scripa., 1985; 32, pp. 257-260. 
[7] Mandelbrot BB, Passoja D, Paullay A., Fractal character of fracture surfaces of metals, Nature 1984; 308: 721-722.

[8] McWilliams PC, Kerkering JC, Miller SM. Estimation of shear strength using fractals as a measure of rock fracture roughness. Bureau of Mines RI 9447; 1993.

[9] Sayles RS, Thomas TR. The spatial representation of surface roughness by means of the structure function: A practical alternative to correlation, Wear 1977; 42: 263-276.

[10] Thomas A. Structure fractal de l'architecture de champs de fractures en millieu rocheux, Comptes rendus de l'académie des sciences de Paris Série II 1987 ; 4 : 181-186.

[11] Xie H, Wang JA, Xie WH. Fractal effects of surface roughness on the mechanical behavior of rock joints. Chaos, Solitons Fractals 1997; 8:221-52.

[12] Xie H, Wang JA. Direct fractal measurement of fracture surface. Int J Solids Struct 1999; 36: 3073-84.

[13] Yang Z.Y., Di C.C. Adirectional method for directly calculating the fractal parameters of joint surface roughness. Int J Rock Mech Min Sci 2001; 38:1201-1210.

[14] Hadjigeorgiou J., Grenon M. \& Lessard J.F., Defining In-Situ Block Size. 99th CIM Annual General Meeting- Rock Mechanics and Strata Control, Vancouver 1997.

[15] Dershowitz W. S., Einstein H. H. Characterizing rock joint geometry with joint system models, Rock Mech and Rock Eng 1988, 21: 21-51.

[16] PR La Pointe, Pattern analysis and simulation of joints for rock engineering. In: In: Comprehensive rock engineering, Pergamon Press, J A Hudson, ed, vol. 3, 1993.

[17] Lanaro F. A random field model for surface roughness and aperture of rock fractures, Int J Rock Mech Min Sci 2000; 37:1195-1210.

[18] Baecher GN, Lanney NA, Einstein HH. Statistical description of rock properties and sampling. In: Proceedings of the 18th US Symposium on Rock Mechanics, 1977. p. 1-8. 
[19] Billaux D, Chiles JP, Hestir K, Long J. Three-dimensional statistical modelling of a fractured rock mass - an example from the Fanay-Augères Mines. Int J Rock Mech Min Sci \& Geomech Abstr 1989; 26: 281-299.

[20] Cruden DM. Describing the size of discontinuities. Int J Rock Mech Min Sci and Geomech Abstr 1977; 14:133-137.

[21] Dershowitz WS, Herda HH. Interpretation of fracture spacing and intensity. In: Proceedings of the 33rd US symposium on Rock Mechanics, Santa Fe, NM, 1992. p. 757-66.

[22] Hamdi E., Du Mouza J. A methodology for rock mass characterisation and classification to improve blast results. Int J Rock Mech Min Sci 2005; 42:177-194.

[23] Kulatilake PHSW, Wu TH. Estimation of mean trace length of discontinuities. Rock Mechanics and Rock Engineering 1984;17:215-232.

[24] Kulatilake PHSW. Application of probability and statistics in joint network modeling in three dimensions. In: Proceedings of the Conference on Probabilistic Methods in Geotechnical Engineering, Canberra, Australia, 1993. p. 63-87.

[25] Lyman G.J. Rock fracture mean trace length estimation and confidence interval calculation using maximum likelihood methods. Int J Rock Mech Min Sci 2003; 40:825-832.

[26] Mauldon M. Estimating the fracture trace length and density from observations in a convex window. Rock Mech Rock Eng 1998; 31(4):201-16.

[27] Pahl PH. Estimating the mean length of discontinuity traces. Int J Rock Mech Min Sci Geomech Abstr 1981; 18:221-8.

[28] Xu J, Cojean R. Three-dimensional simulation of natural rock granulometry. In: Price DG editor. Proceedings of the $6^{\text {th }}$ International Congress on IAEG. Rotterdam: Balkema; 1990. p. 797-802.

[29] Priest SD, Hudson J. Discontinuity spacing in rock. Int J Rock Mech Min Sci and Geomech Abstr 1976; 13:135-148. 
[30] Zhang L, Einstein HH. Estimating the mean trace length of rock discontinuities. Rock Mech Rock Eng 1998; 31(4):217-35.

[31] Zhang L, Einstein HH. Estimating the intensity of rock discontinuities. Int J Rock Mech Min Sci 2000; 37: 819-37.

[32] Ayalew L., Reik G., Busch W. Characterizing weathered rock masses-a geostatistical approach. Int J Rock Mech Min Sci 2002; 39: 105-114.

[33] Chilès JP. Fractal and geostatistical methods for modelling of a fracture network, Mathematical Geology 1987; 20: 631-654.

[34] Chilès JP. Three-Dimensional geometric modelling of a fracture network, In: Geostatistical Sensitivity, and Uncertainty Methods for Ground-Water Flow and Radionuclide Transport Modelling, BE. Buxton, ed. Battle press, 1989, pp 361-385.

[35] Chilès JP, Bourgine B, Castaing Ch, Genter A, Wendling J. Caractérisation et simulation multi-échelles de réseaux de fractures de réservoirs pétroliers, Cahiers de géostatistique 1998 ; $6: 105-116$.

[36] Chilès JP, Bourgine B, Castaing Ch, Genter A. Stochastic modelling and simulation of fracture networks in petroleum and geothermal reservoirs, Cape Town- Geostats 2000; 1: 413423.

[37] Gentier S., Riss J., Archambault G., Flamand R., Hopkins D. Infuence of fracture geometry on shear behavior. Int J Rock Mech Min Sci 2000; 37:161-174.

[38] Gentier S, Chilès JP, Riss J. Analyse et simulation d'une surface de fracture rocheuse, Compte-rendu des Journées de Géostatistique-Fontainebleau- Cahiers de Géostatistique 1991; pp 77-87.

[39] Hestir K, Long J, Chilès JP. Some techniques for stochastic modelling of threedimensional fracture networks, In: Geostatistical Sensitivity, and Uncertainty Methods for 
Ground-Water Flow and Radionuclide Transport Modelling, BE. Buxton, ed. Battle press, 1989, pp 495-519.

[40] Massoud H. Modélisation de la petite fracturation par les techniques de la géostatistique, Thesis, E.N.S. des Mines de Paris 1987.

[41] Laboratoire Régional des Ponts et Chaussées de Toulouse, Aménagement entre Villefranche de Conflent et Mont-Louis, Compte rendu du projet 2005.

[42] Jimenez-Rodriguez R, Sitar N. Spectral method for clustering of rock discontinuity sets, Int J Rock Mech Min Sci 2006 ; 43: 1052-1061.

[43] Priest SD. Discontinuity analysis for rock engineering. New York: Chapman \& Hall, 1993. [44] Priest SD, Hudson JA. Estimation of discontinuity spacing and trace length using scanline surveys, Int J Rock Mech Min Sci 1981; 18(3): 183-97.

[45] Armestrong M. Basic Linear Geostatistics. New York: Springer, 1998.

[46] Journel AG, Huijbregts C J. Mining Geostatistics. New York: Academic Press, 1978.

[47] Journel AG , Froidevaux R. Anisotropic hole-effect modeling. Mathematical Geology 1982;14(3): 217-239.

[48] Press WH, Flannery BP, Teukolsky SA, Vetterling WT. Numerical recipes in C. Cambridge: Cambridge University Press; 1988.

[49] Kalenchuk KS, Diederichs MS, McKinnon S. Characterizing block geometry in jointed rockmasses, Int J Rock Mech Min Sci 2006; 43: 1212-1225.

[50] Meyer T, Einstein HH. Geologic Stochastic Modelling and connectivity assessment of fracture systems in the Boston area, Rock Mech and Rock Eng 2002; 35(1):23-44.

[51] Einstein HH. Modern developments in discontinuity analysis the persistence discontinuity problem. In: Hudson JA, editor. Comprehensive rock engineering, volume 3 rock testing and site characterization. New York: Pergamon Press; 1993. p. 215-39. 
[52] Lee JS, Veneziano D, Einstein HH. Hierarchical fracture trace model. In: Hustrulid WA,

Johnson GA, editors. Rock mechanics; contributions and challenges; proceedings of the 31st

U.S. symposium.Rotterdam: A.A. Balkema; 1990. p. 261-268.

Table 1

Direction of average unit normal vectors for each discontinuity set, obtained from Fig.3, number of fractures and real spacing distance (in $\mathrm{cm}$ ) for each set.

\begin{tabular}{ccccc}
\hline Set & Number of fractures & Dip & Direction of dip & Real spacing average(cm) \\
\hline $1+$ & 117 & 8 & 193 & 17.65 \\
$2 \Delta$ & 88 & 8 & 94 & 96.9 \\
$3 \circ$ & 78 & 17 & 308 & 88.15 \\
$4 \times$ & 32 & 51 & 305 & 140 \\
\hline
\end{tabular}

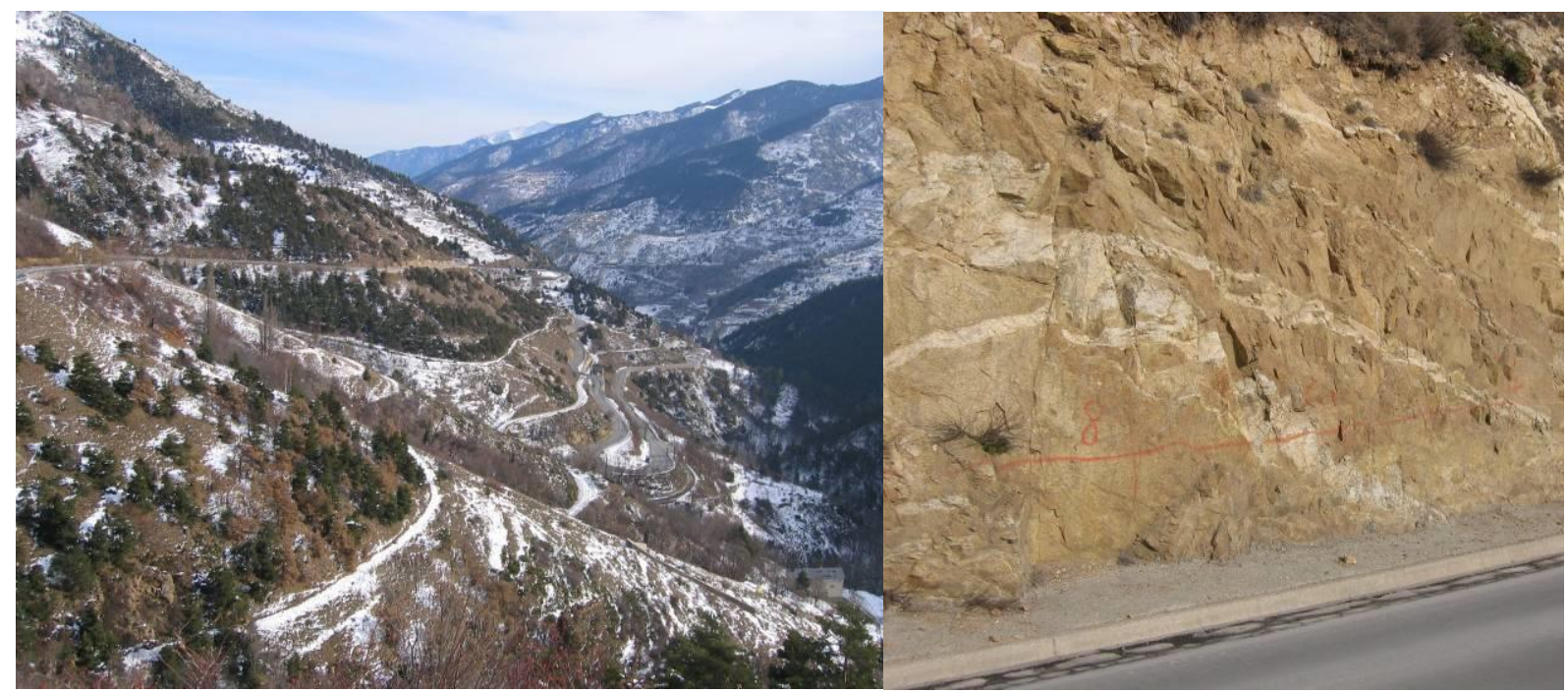

Fig. 1. Left: Panoramic view of the sector of Pallat, showing the existence of danger due to rock mass instabilityRight: close-up of the fracture system at the road side outcrop, and measuring scanline. 


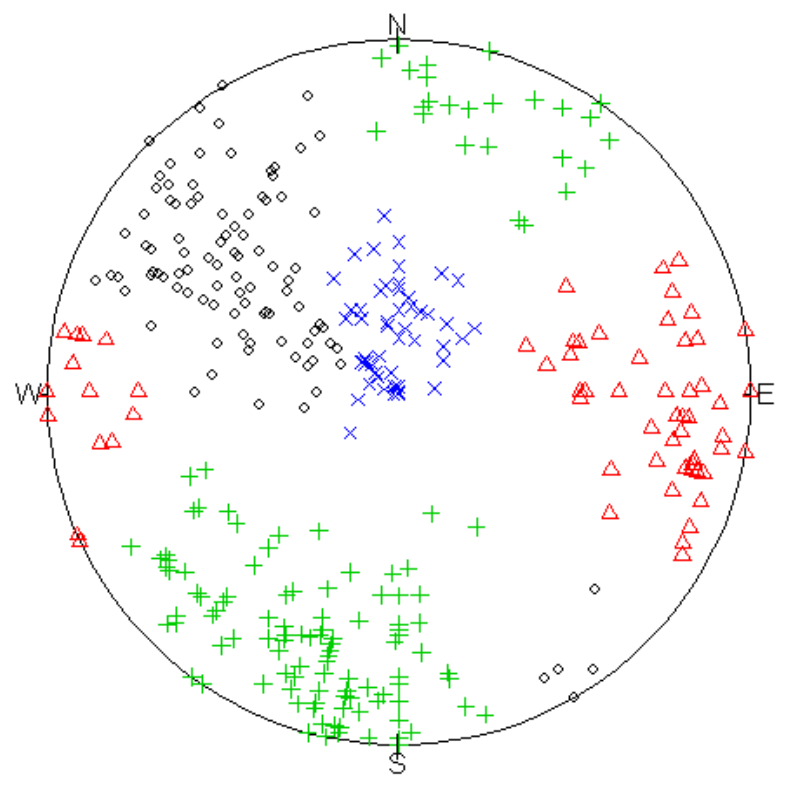

Fig. 2. Spectral clustering in four principal sets of the 392 discontinuity orientations measured in the migmatite rock mass, projected in the lower hemisphere system- Pallat ravine. 


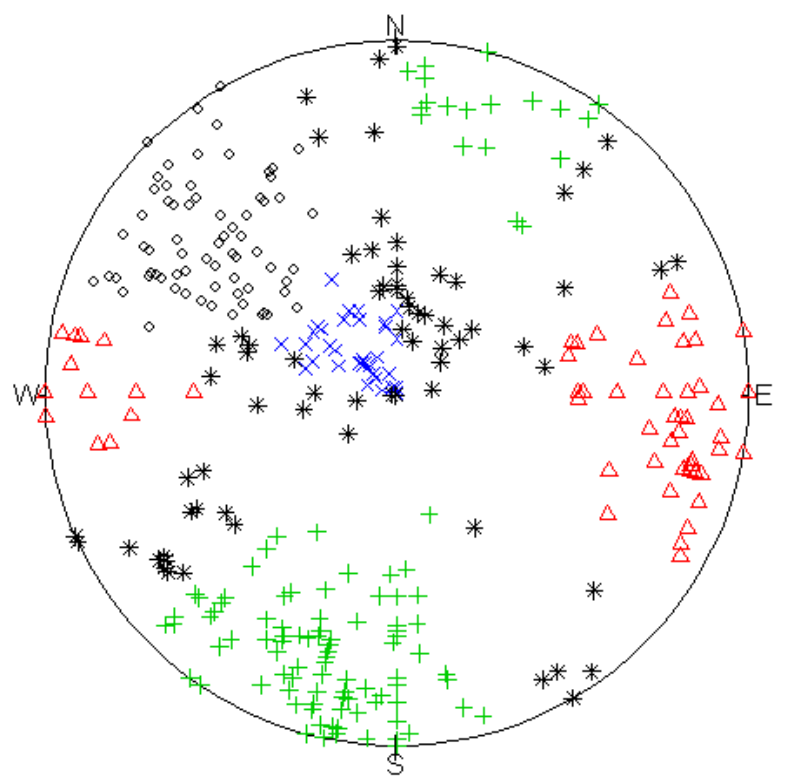

Fig. 3. Spectral clustering in four principal sets of 315 discontinuity orientations projected in the lower hemisphere system-by considering the vicinity of $25^{\circ}$. The points shown in * symbol belong to no family and are considered as outliers. 


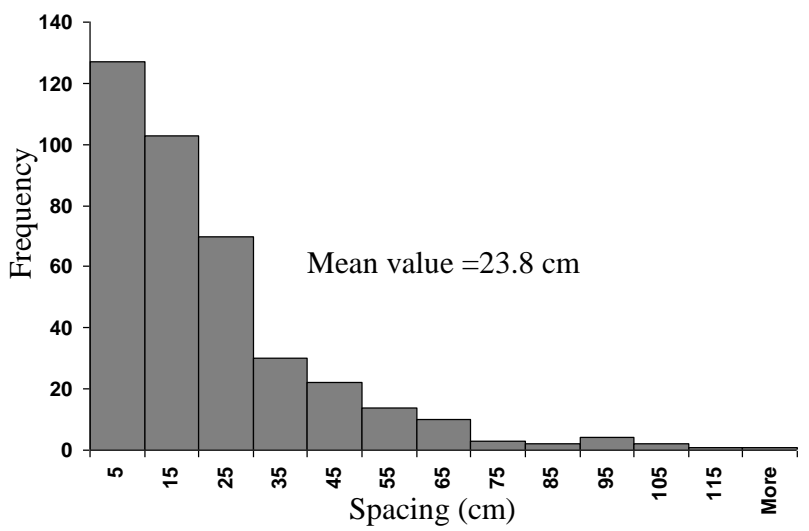

Fig. 4. Frequency histogram of the discontinuity spacing, from 392 factures measured on the scanline 1 in migmatite, Pallat ravine. 


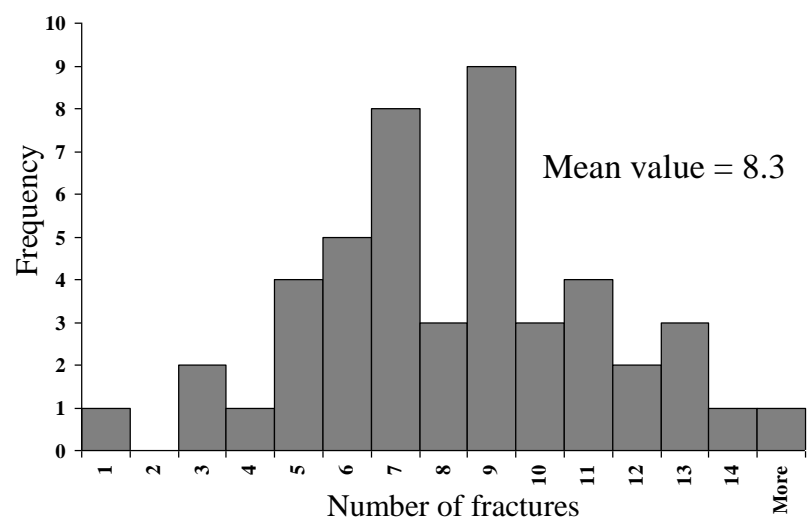

Fig. 5. Frequency histogram of the number of fractures (per $2 \mathrm{~m}$ segments) from 392 discontinuities measured on scanline 1 in migmatite, Pallat ravine. 


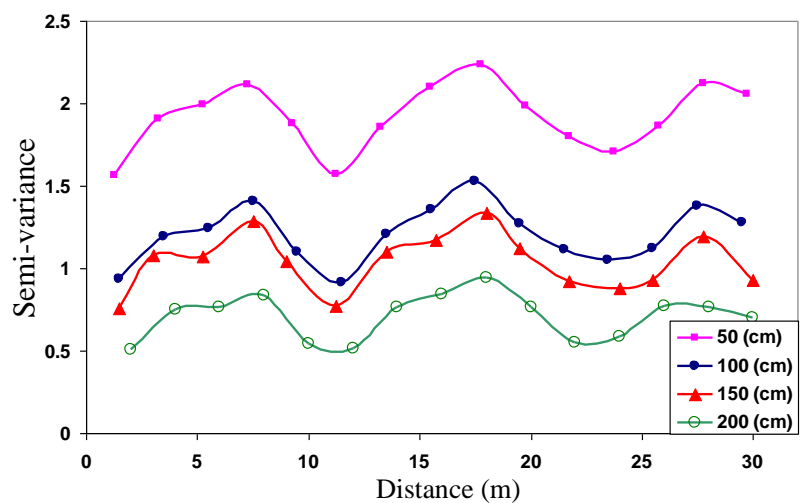

Fig. 6 Average semi-variogram of fracture densities for the segment sizes of $0.5 \mathrm{~m}, 1 \mathrm{~m}, 1.5 \mathrm{~m}$ and $2 \mathrm{~m}$. 

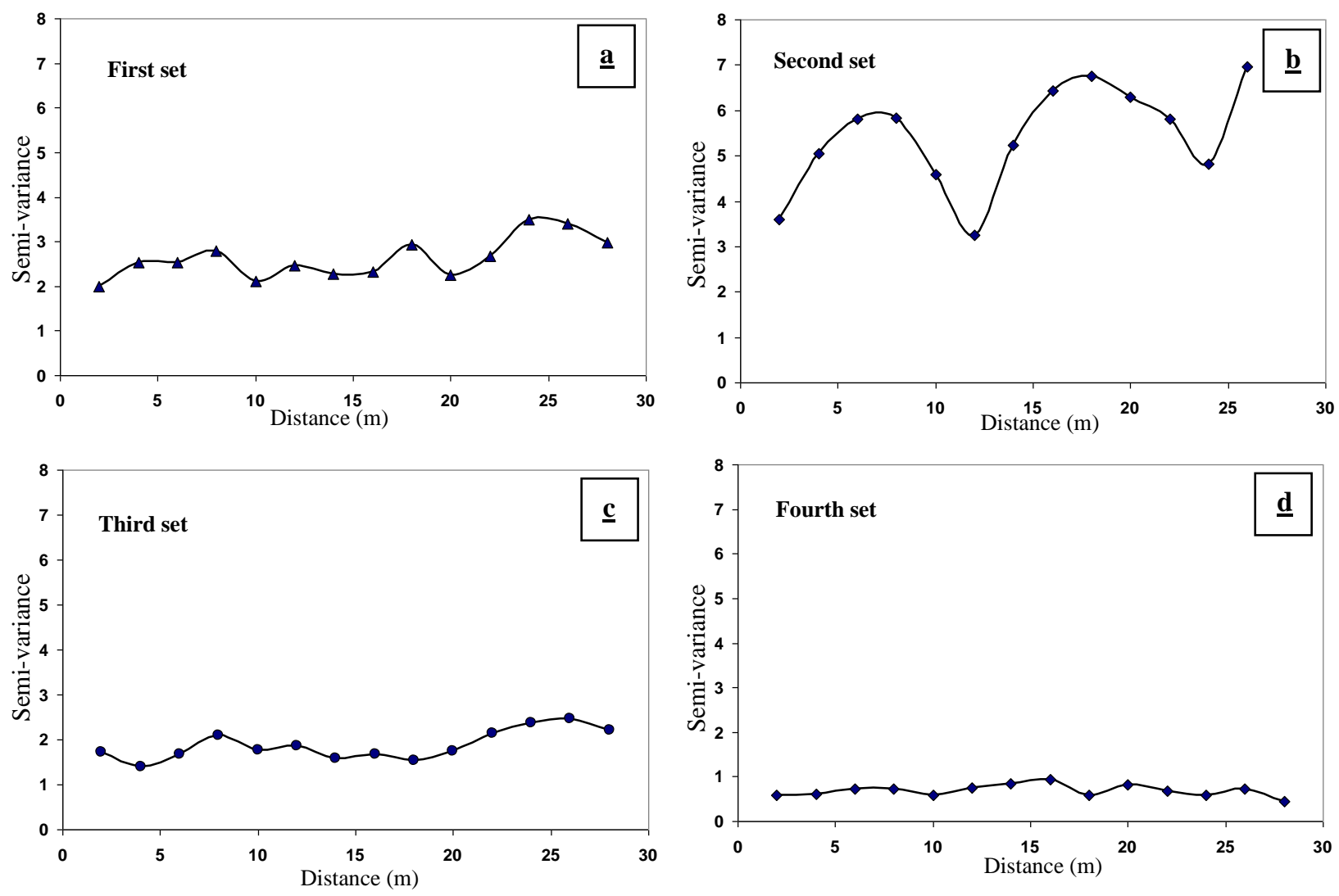

Fig. 7. Semi-variograms of the fracture densities for $2 \mathrm{~m}$ segments from the different discontinuity sets. (a) first set, (b) second set,(c) third set and (d) fourth set. 


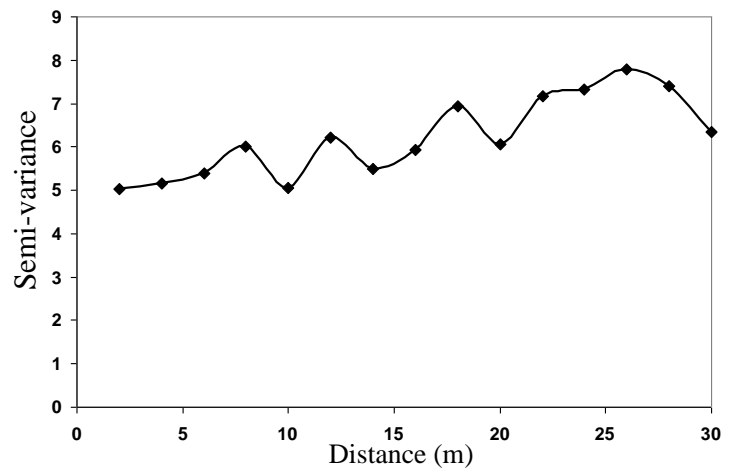

Fig. 8. Semi-variogram of the fracture density for $2 \mathrm{~m}$ segments from all the discontinuities measured on the scanline, without the discontinuities belonging to the second set. 


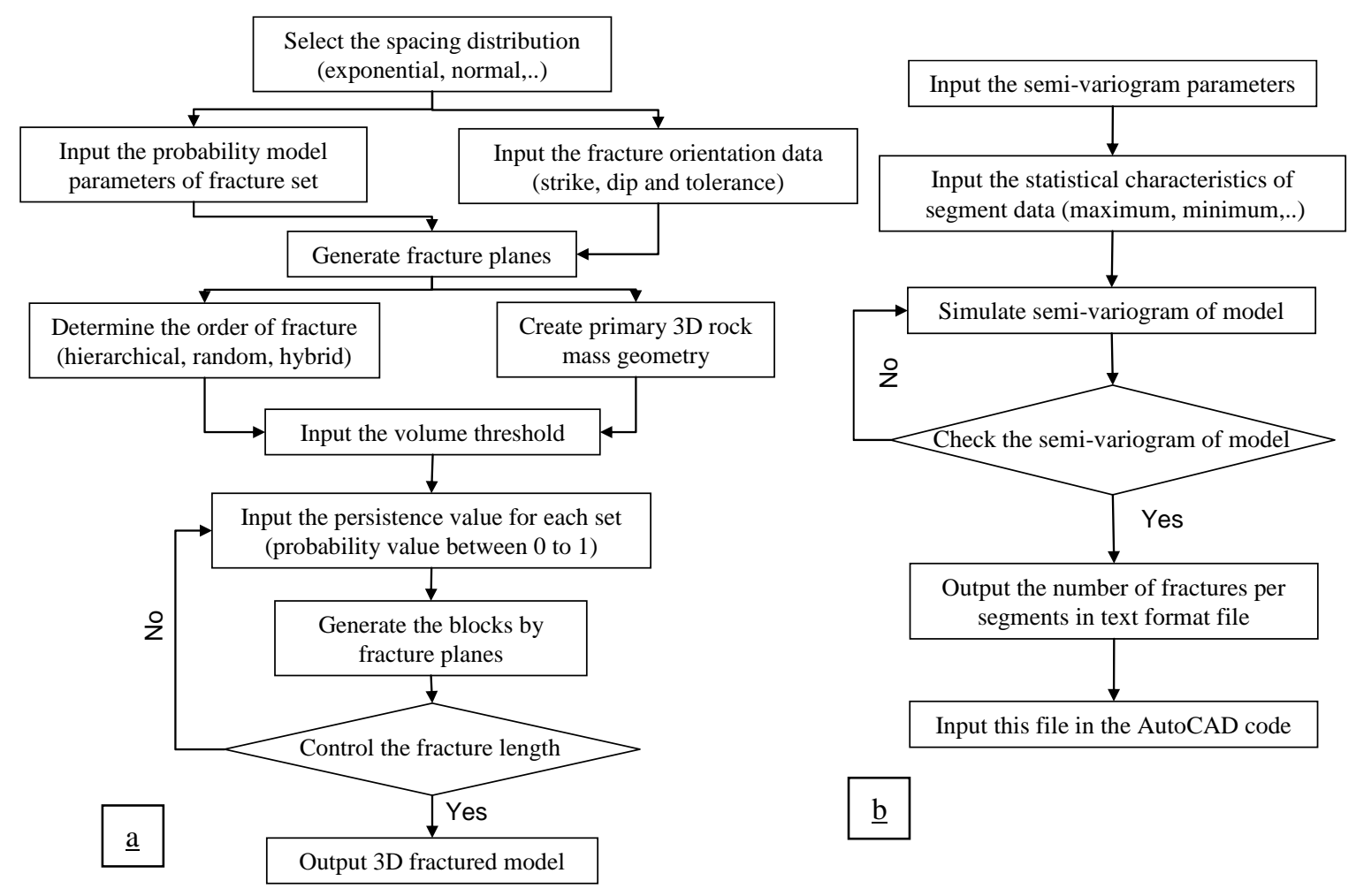

Fig. 9 Flowchart of 3D fractured rock mass modelling: (a) 3D model without semi-variogram structure (Auto $\mathrm{CAD}$ ) and (b) 3D model with hole-effect structure in the semi-variogram ( $\mathrm{R}$ environment). 


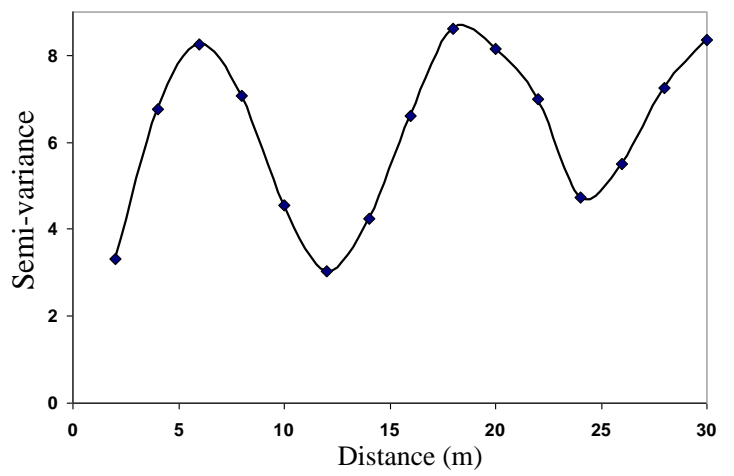

Fig. 10. Model results: Semi-variogram of the fracture densities for $2 \mathrm{~m}$ segments from the discontinuities generated on the basis of the second fracture data set (compare with Fig.7b). 

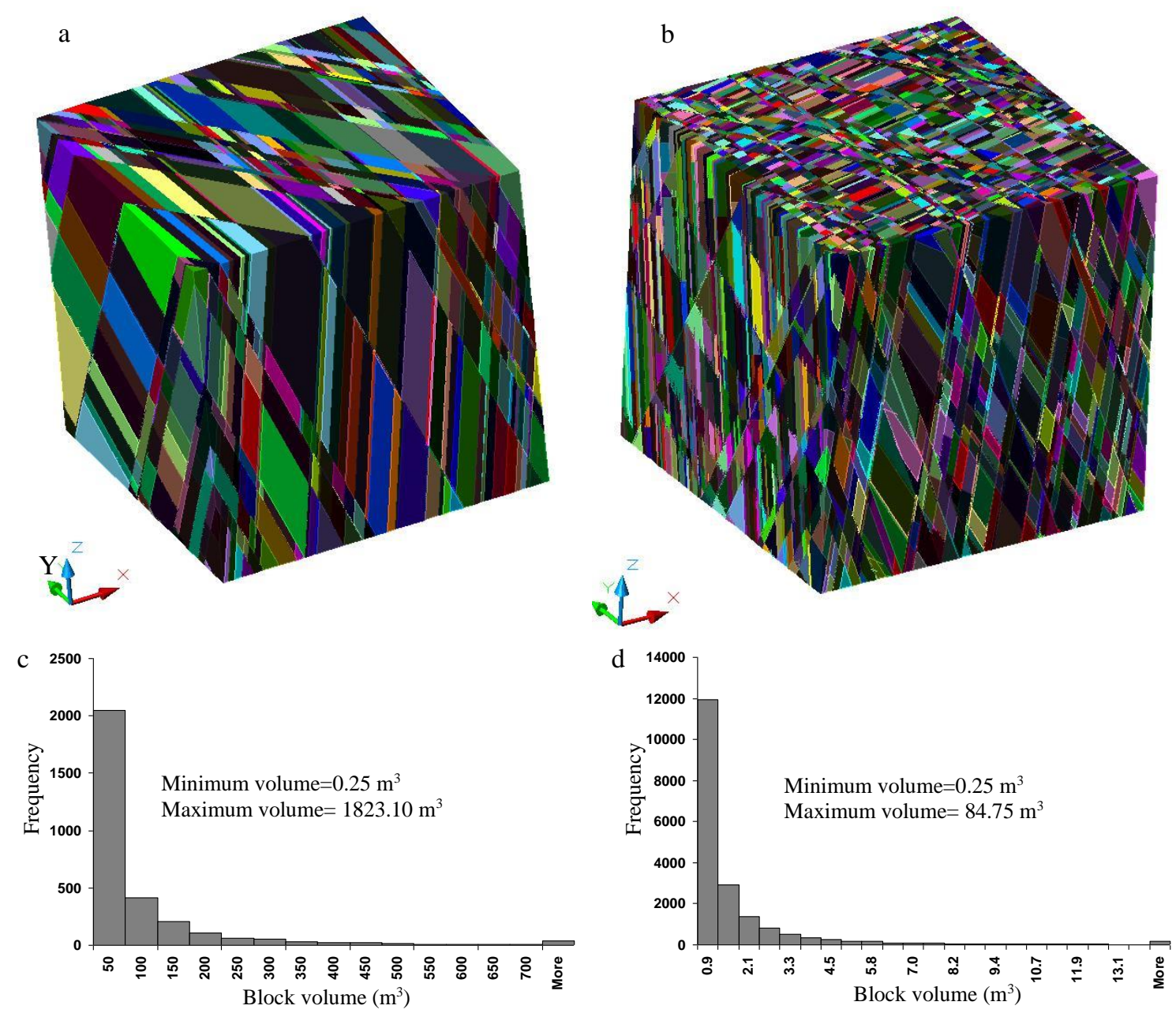

Fig. 11. Simulated rock mass in a $(30 \mathrm{~m} * 30 \mathrm{~m} * 30 \mathrm{~m})$ cube and corresponding block volume histogram: (a) stochastically generated jointed rock mass by two fracture sets including first and second sets ( $\mathrm{Y}$ axis is the North direction); (b) stochastically generated jointed rock mass with all four fracture sets; (c) the histogram of block volume distribution for the rock mass model shown in (a); the histogram of block volume distribution for the final rock mass model exhibited in (b). 